far overtaxed hospitality of the JoUnNaL, and ask attention to the accompanying woodcut from an untouched photograph taken three months after operation.

The case now briefly reported is that of an unmarried American missionary lady, aged 26 , who, without any history of local injury, noticed, in February, 1892, a nodule, the size of a large bean, in the lower external quadrant of the right breast. There was no family history of any significance. Menstruation had been established at 14, and the periods had ever since been in every respect normal. She was seen on May 12th, 1893, when, in the position indicated, a smooth, somewhat elastic, spherical tumour, perfectly movable, about the size of a large walnut, was perceptible about half way through the depth of the gland. It was slightly sensitive to pressure; it underwent no change of any kind during inenstruation, but, independently of this, had lately become the seat of severe paroxysmal pain, lasting for a couple of hours at a time, and then disappearing completely for seven days. Nipple and areola normal. In the lower hemisphere of the left breast there were a number of small, hard, indolent nodules, evidently lobules of the gland. These disappeared

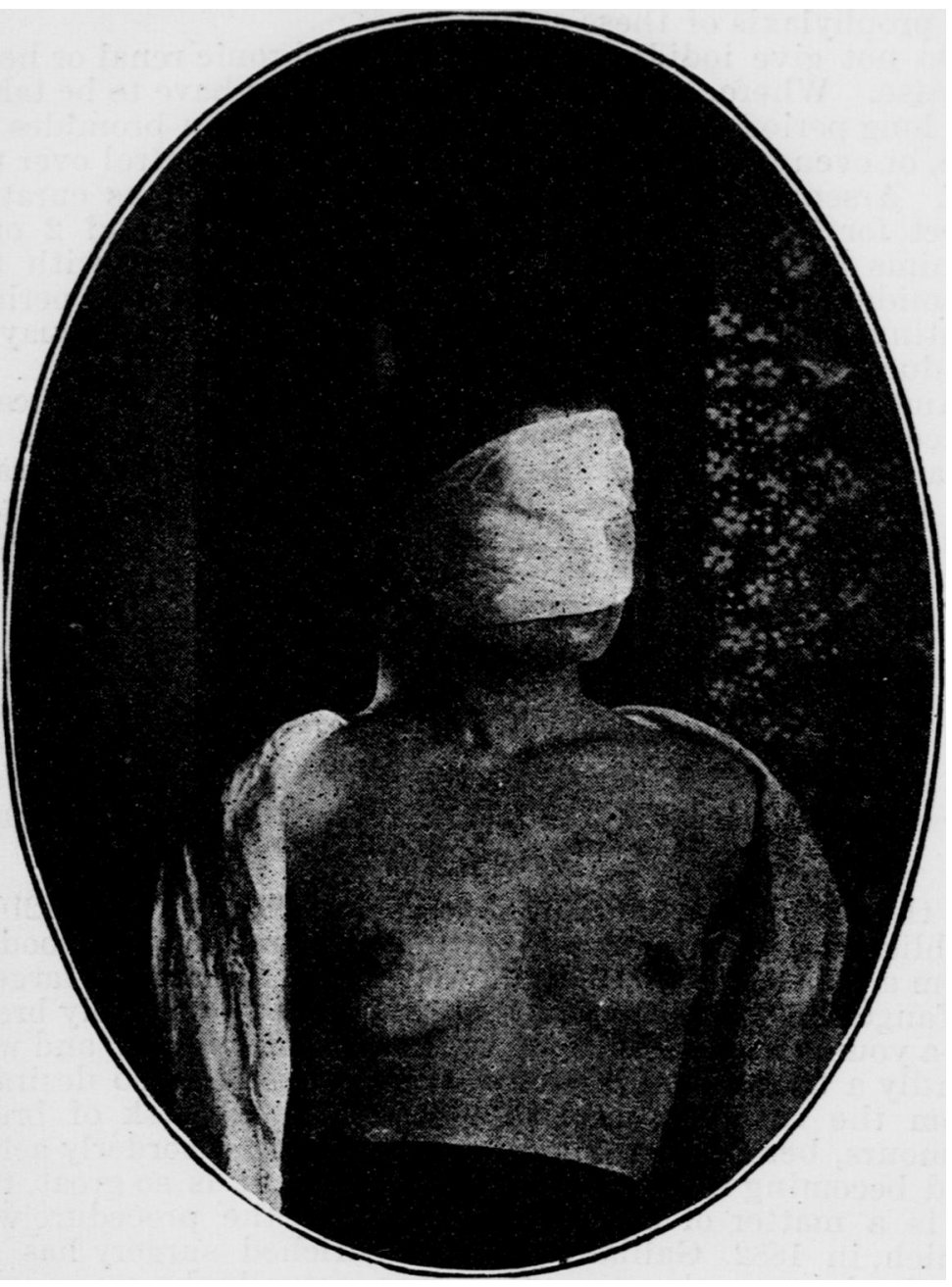

completely within a fortnight after operation on the right breast, and were evidently due to sympathetic irritation. Precisely the same phenomena had been observed in one of my previous cases.

The operation previously described was performed, and the tumour was easily shelled out from behind. It proved to be an example of the ordinary non-cystic adeno-fibroma of young women. There was no suppuration. On the twenty-second day, the wound being then soundly healed, the patient left for her mission station, where she at once contracted typhoid fever. From this she was convalescent in three weeks, and the disease appeared to have no hurtful influence on the consolidation of the site of the operation.

On A ugust 3rd, 1893, the breast was photographed : and on the following day the patient married. Six weeks later I saw her, and it is perhaps worthy of note that, although both breasts had considerably enlarged since marriage, no pain had been induced in the nperated gland, which, as will be seen, had perfeotly.preserved its natural shape.

\section{OVARIOTOMY DURING PREGNANCY.}

BY E. HOOPER MAY, F.R.C.S.

Surgcon, Tottenham Hospital

Mrs. C., aged 22, was admitted into the Tottenham Hospitab on April 5th, 1893. She was a pale, delicate-looking, diminutive woman, with an anxious expression and an enormously distended abdomen. She was probably at about the end of the eighth month of pregnancy. She had been insufficiently nourished of late. She had been married four years, and had had one child, now 2 years old; no miscarriages. Menstruation was regular till her firet pregnancy; she had not menstruated since. She suckled the child till after it ran about. During the summer of 1892 she first noticed that her abdomen was becoming prominent. She had then some swelling of the legs, which had since gone down. The abdomen continuing to increase in size, she attributed her condition to pregnancy. At Christmas the abdomen appeared to be nearly as large as when admitted. The measurement on admission was 50 inches in circumference at the umbilicus, and 27 inches from the ensiform cartilage to the pubes.

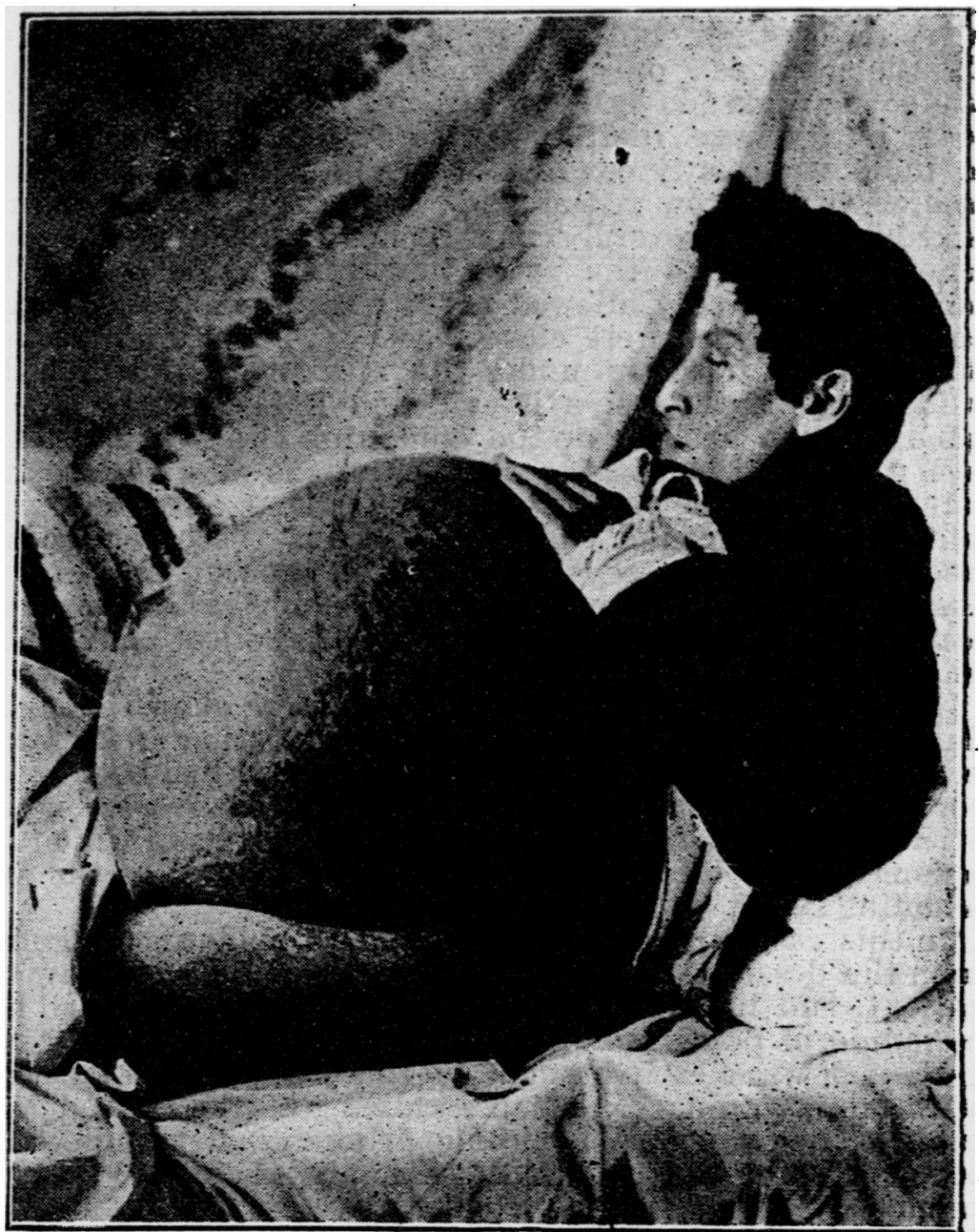

Palpation gave the impression of the presence of a large cyst. On vaginal examination the os uteri was felt high up and far back; it could just be reached by the finger tip, and was felt to be soft and open enough to admit the tip of the finger. What seemed to be a child's head could be just felt. Notwithstanding the late period of pregnancy, on account of the patient's half-starved condition it was thought best to feed her carefully for a few days before operating.

She improved rapidly in appearance, and on April 12th at 3 P.M. the operation was done. On opening the peritoneum adhesions were found, and the wound was enlarged quite up to the umbilicus, about $4 \frac{1}{2}$ inches altogether. Slight parietal adhesions were broken down, and the cyst tapped, about 36 pints of brown fluid escaping. More slight adhesions were then broken down, giving rise to very slight bleeding, and one large strong parietal adhesion and one to the omentum were ligatured and divided. The pedicle, which was about an inch wide, was tied in the usual way, and the peritoneal layers were stitched together over the face of the stump with 
a continuous suture of catgut. The wound in the abdominal wall was then closed by continuous catgut sutures, the peritoneum, muscles, and skin being each stitched separately.

The operation was very well borne. As the patient recovered consciousness she became very wild and restless. She soon began to complain of pain in the abdomen, and it became evident that labour had commenced. A healthylooking male infant was born about 3 A.M., twelve hours after the commencement of the operation. The pulsation of the cord had ceased, and no sign of respiration was observed. The placenta was soon removed. and there was very little hæmorrhage. The wound was redressed, and appeared to be quite undisturbed. The patient was then quiet and comfortable. After this recovery was uninterrupted. The greatly stretched skin of the abdomen shrank into a flat, brown, rugged surface, the wound looking remarkably small and firm.

\section{THYROID FEEDING IN EXOPHTHALMIC} GOITRE.

By DAVID OWEN, M.R.C.S., L.S.A., Manchester.

Now that the use of thyroid gland in the treatment of disease is receiving so much attention, the following case may be of interest.

IV. U., aged 46, a labourer, came under observation last May on account of an attack of diarrhœa, which had kept him awake the whole of the night before. He said that for twenty years he had had a swelling in the neck and a prominence of the eyeballs. Several doctors had noticed these peculiarities. During that time he had suffered much from palpitation and breathlessness, which rendered him unable to do a good day's work.

His face wore a very anxious expression, the eyeballs were very prominent, a wide ring of sclerotic being visible; the upper eyelids did not accompany the eyeballs in downward movement, and carrying the hand rapidly in front of his eyes did not cause blinking. There was visible arterial throbbing in the neck, and a fulness in the thyroid region protruding well in front of the anterior bo:der of the sterno-mastoid muscles. Pulse 126. The apex beat was in the sixth intercostal space just outside the nipple line. The upper margin of the cardiac dulness was in the third intercostal space, the right margin at the left border of the sternum. No murmur was detected. There was no albumen in the urine.

The diarrhoe was checked by opium. Then quinine, iron, digitalis, and arsenic were given for a fortnight without benefit. He was then put upon raw sheep's thyroid (a quarter lobe per diem), minced and flavoured with a little sait and vinegar. His wife gave him, through a misunderstanding, 1 lb. daily for two days. This caused dyspeptic symptomsnausea, eructations, vertigo, and insomnia. His face and legs swelled, in consequence, he thought, of the " neckbergs," by which name thyroids are known to butchers in this locality. The thyroid was discontinued for a week, and the unpleasant effects of the previous mistake having passed off, was resumed in the quantity originally prescribed. He steadily improved, and for the last three months has been able to do heavy work without the slightest discomfort-an experience unknown to him, he says, for many years. The exophthalmos is now scarcely perceptible, and would not be suspected without close examination. There is now a depression in place of the previous fulness in the thyroid region. The pulse is 76. The area of cardiac dulness is unaltered. Arterial throbbing has disappeared. The patient is greatly surprised at the change which has come over him, and continues to take a quarter of a lobe twice a week. One cannot be sure that there is a connection between the treatment and the improvement, though the patient has no doubt on the matter.

Medical Students in Switzerland.-The number of students in the medical faculties of the universities of Switzerland during the summer semester of 1893 are officially stated to have been as follows:-Zürich, 297 ; Geneva, 224; Bern, 224 ; Basel, 152 ; and Lausanne, 84.

\section{MEMORANDA; \\ MEDICAL, SURGICAL, OBSTETRICAL, THERA- PEUTICAL, PATHOLOGICAL, Etc.}

\section{LARGE CONGENITAL MENINGOCELE.}

On the evening of August 6th, 1893, I was called to Mrs. $H$. in her second confinement. On my arrival I found the head at the outlet. Some little delay occurred before the head was fully born. Immediately following the escape of the head was a tumour considerably larger than the head itself, depending from the back of the occiput to the shoulders. This proved to be a large meningocele consisting of a membranous bag nearly full of fluid, and measuring in circumference :

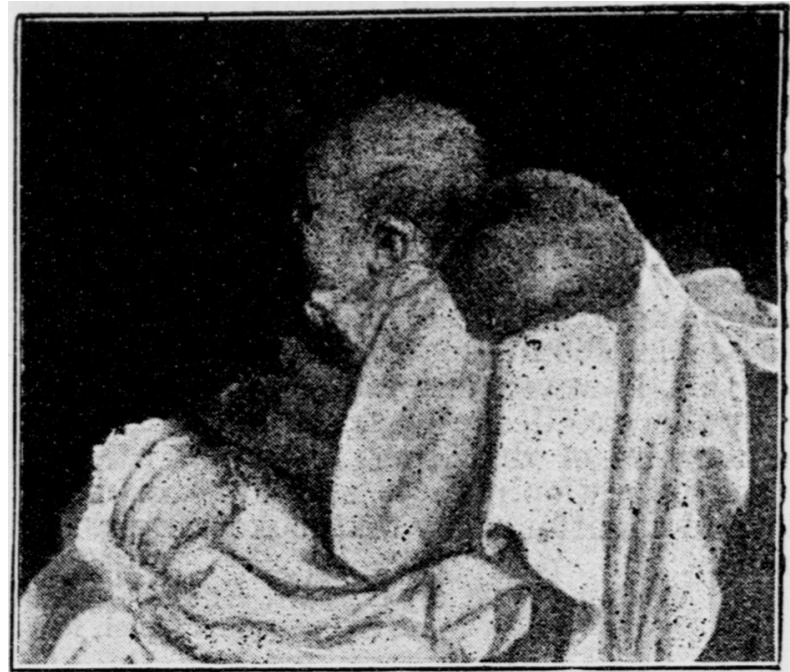

laterally 19 inches, and in the antero-posterior direction 12 inches. The child's features were peculiar and old looking, the nose much flattened; in other respects the child (a female) was a fine and well-formed one.

The mother had been delivered fourteen months previously of a fine healthy child, which is still living. She is unable in any way to account for the malformation in this case.

On August 8th a medical friend saw the child with me, and there being no likelihood of it surviving long, we agreed that nothing should be done to the tumour beyond supporting it in cloths.

The child took the breast well. The surface of the tumour soon became congested, and ulcerated in patches. On August 12th the ulcerated patches had become very thin, and appeared likely to give way at any moment. For several days the child had slight convulsions, and seemed much pained when moved. Under these circumstances I deemed it best to evacuate the tumour, which I did by puncturing it with a small trocar. Upwards of a pint of amber-coloured fluid was thus drawn off. The child was evidently much relieved by the tapping, and slept quietly for eight hours, and the convulsions ceased. On August 14th the fluid had reaccumulated to some extent; the child had become restless and continued to cry. I therefore again punctured the sac and withdrew nearly half a pint of fluid. On August 16th the sac, which had refilled, gave way at one of the ulcerated spots, discharging a considerable quantity of fluid. The child then became much worse; severe convulsions followed, and it died at 7.30 P.M. On August 17th, eleven days from its birth.

On post-mortem examination, it was found that a fissure existed on either side of the lower part of the occipital bone; that on the right side communicated with the sac, and admitted the passage of my forefinger. The fissure on the left side was closed by membrane, and appeared to have no communication with the sac. The photograph was taken the second day after birth.
Dover.
E. Frnn, M.D.

THE late Mr. James Rea, who rapidly amassed a fortune in Belfast, has left his entire estate to Belfast charities, which will benefit to the extent of at least $£ 100,000$. 